\title{
Second Language Development Through the Use of Dance
}

\author{
Ildiko Pinter \\ Brock University
}

\begin{abstract}
Professionals frequently discuss implicit language learning and teaching techniques, but few language teachers actually use explicit techniques to teach second language. This article discusses the use of dance as a teaching strategy for second language learning. Through dance, students can develop various relationships. Creating relationships between the mind and body, and between the self and the community is very meaningful especially for second language learners. The focus of these relationships is holistic. It is important to begin to use explicit strategies to bring together various domains of knowledge. I propose a variety of tools in which dance can be implemented into the second language curriculum.
\end{abstract}

In an age of mass-communication tools, oral language still remains the preferred form of interaction between individuals. Although oral language is preferred, there are other forms of communication we use and rely on, sometimes even more so than we are aware. Often we read a person's body language and it can tell us more than actual words. The relationship between mind and body is very important and it is one which each student should be given the opportunity to experience. One of the ways this relationship can be explored is through the use of dance. Through dance, individuals develop "muscle sense" or kinesthetic perception of bodily movement. They gain a sense of rhythm, as movement is not isolated but is part of a whole. While dancing, students develop a sense of fluency as their bodies become more centred. As students gain this kinesthetic perception, they learn to express their own feelings and they also increase their movement vocabulary. Dance, then, becomes a vehicle for expressing the inner life of the individual. To date, the functions of dance have been examined from several perspectives. Dance has been seen as emotional experience, nonverbal communication, as a means of establishing social unity, as an expression of the collective unconscious of a society, and as a form of movement. In addition to all of these valuable elements, there are further purposes dance can serve. Using the technique of

Ildiko Pinter is a student in the Graduate Department, Faculty of Education, Brock University. Her interests are second language, holistic education, literacy, curriculum design, memory and cognition, and learning disabilities. 
movement as a means of communication or just as a strategy can enhance the language learning process, especially for second language learners. Different factors such as self-esteem and anxiety can be affected which, in turn, can affect the language learning process. This article explores a holistic approach to language acquisition utilizing dance to help connect the two. Dance, then, is a powerful tool as a means of communication, which needs to be explored and considered as a potential strategy for second language acquisition.

\section{Conditions for Second Language Learning}

The different ways in which students tackle leaming, can affect their success. What happens in the class is not equally productive for all the students because everyone's mind works in different ways. Students also base what they do on previous experience of learning and of using language. Understanding how apparently similar students react differently to the same teaching technique can help second language instructors realize the need for various methods to target the needs of each individual.

Second language (I 2) teaching methods incorporate a view of learning either implicitly or explicitly. In the former, grammar-translation teaching emphasizes explanations of gramnatical points because it fits in with the view that L2 learning is the acquisition of conscious knowledge (Cook, 1996). In the latter, communicative teaching methods make students talk to each other because L2 learning is seen as a growing out of the give and take of communication. L2 learning research has shown that the best way to learn a foreign language is explicitly. For instance, being immersed into an environment, where only that specific language is spoken, is by far the quickest and most efficient way to learn a language. Even though this is a well-known fact, there is still more focus on inplicit methods when teaching a L2.

Obviously, an immersion setting is not always possible, but there are alternative ways in which classroom settings can be focused on, thereby creating more of a realistic environment. One example is to mimic situations in which individuals would encounter themselves in everyday situations. A need for more interaction and communication amongst peers in a L2 setting is a definite must. Learners are individuals and factors such as motivation, anxiety, age, personality, and level of first language, can also contribute to the learning process. Thus, it is important to be aware of the various conditions for L2 learning, as well as to give equal importance and opportunity for explicit learning strategies. 


\section{Holistic Education}

The value of holistic educational processes is derived directly from their humanistic nature. Humans are not divided into separate components; rather, cognitive learning, emotions, values, and day-to-day behaviour are deeply intertwined in each learner. These factors influence and mutually affect one another. Unifying the portions of these spheres of humanness is likely to render the educational process more effective (Miller, 1996). To recognize the multi-dimensional nature of human experience by honouring the emotional/ psychological, physical and spiritual, and the cognitive needs of the learner, as well as the imate potential of every student, is the basis for holistic education which derives from a humanistic perspective. Using a holistic approach to learning implies the notion of connectedness. It involves exploring and making relationships in a variety of ways. One of these connections is the relationship between mind and body. A holistic curriculum explores the relationship between mind and body so that the student senses the connection between the two.

\section{Dance Education}

The more exposure one has to language teaching and dance, the more aware one becomes of the many parallels that exist between the two domains. Although some teachers feel that they are able to offer students the opportunity to encounter language in purposeful and challenging contexts, the idea of incorporating movement into their language teaching has not occurred to them because it is a relatively new concept. Since there has been no information given in this field, there is the obstacle of how to go about incorporating something like dance into language learning. The following sections will help in getting started.

There are many concepts associated with the teaching of foreign languages that are also essential to dance. What are some parallels between language teaching and dance? Most fundamentally, dancers and language learners share common goals, the most important being effective "performance," that is, communicating the intended, appropriate message. In order to communicate, dancers, like language learners, have to be able to do three things (Smith, 1984):

1. They have to be able to decide what they want to communicate, (i.e., what is appropriate for the given situation?)

2. They must then decide how to communicate that message.

3. Finally, they must have the flexibility to implement their decisions, or in 
other words, they must be able to perform with competence. This is perhaps the most difficult task of all.

Dancers and language learners also share common obstacles in learning to convey meaning. They must learn to deal with new language and new roles, to understand their own inhibitions and confusing habits, and to develop the ability to control their own instruments; that is, their bodies, their voices, and their minds. Dancers and language learners can make use of the same strategies in overcoming the obstacles that stand in the way of effective communication.

In order to become skilled at interacting spontaneously in the second language, L2 learners need the opportunity to practise language without inhibition and without interruption from the teacher. However, learners also need to receive correction and explanation from the teacher. A set of movement activities as a pedagogical instrument provides both the freedom and the motivation for learners to develop skills in spontaneous communication. This allows for individual learner differences and allows students to be exposed to language that is realistic.

\section{Dance Techniques for the Second Language Classroom}

The use of dance techniques and methods in language teaching are innovative and offer a good deal of variety. This next section focuses on specific features that dance brings to the classroom and investigate how these influence individual participants and the class as a group. Many programs cannot, practically, accommodate a class devoted entirely to dance techniques. Thus, it is important to keep in mind that the following recommendations and exercises are meant to serve as examples and to suggest ways for readers to create applications of their own for a variety of teaching contexts.

\section{Incorporating Dialogue within the Dance}

It is important to note that when using dance as a teaching strategy for language learning, dialogue can be and in fact should be incorporated for most part of the movement activity. This can occur simultaneously and/or subsequently to the movement activity. Some of the areas of language that are being learned through such processes are grammar, language functions, culture, pronunciation and intonation, language "coping" strategies like paraphrasing, role playing, appreciation of underlying meaning (i.e. analyzing individuals and situations using available linguistic data), appreciation of nonverbal communication, interpretation of subtext (i.e., reading between the lines), using the script as literature and analyzing it as a chunk of discourse, observation 
skills, communication (i.e., self-expression), empathy, exploitation of the memory

(i.e., kinesthetic memory, tonal memory, and sense memory), sensitivity to speech dynamics like tempo and rhythm, self-confidence in using the "second" language, and lexical, physical, and emotional vocabulary (Holden, 1981; Kao \& O'Neill, 1998; Lang, 1993; Smith, 1984; Spolsky, 1989).

The instructor or the students can bring in music. Or, students can create their own and then play it along with the dance activity. The music should include lyrics so that the students can analyze the words and meaning of the song. This adds variety as well as incorporates listening skills into the second language learning environment.

\section{Cultural Education}

The teaching of culture is divided into two categories: coping strategies and knowledge. Knowledge about a specific culture can be learned through various dance activities. Skills that can be useful in cross-cultural interactions can also be developed. The best thing that can be done for language learners is to help them learn about culture on their own. Perhaps the most difficult task a person faces when living in a foreign culture is the interpretation of experiences. The more skilled the language learners become, the more adept they will be at acquiring cultural knowledge.

Hence, it is important to incorporate activities that involve cultural knowledge for the second language learner. They become more aware of their environment and they develop coping strategies that make them more adaptable to their living conditions. One way this can be done is to split the class into pairs or small groups to create short, realistic interactions. These scenarios can be created by the students or by the instructor. An example of how cultural knowledge can be used in an activity is by acting out a Christmas dinner typical in a North American Christmas celebration. Incorporating information on the types of foods eaten, the language used at the dinner table, customs, traditional songs and dances. Such experiences contribute to the language learners verbal as well as cultural vocabulary.

\section{Observation Tasks}

Use observation assignments and discussions to make students aware of opportunities they have to gather information about the target language and culture by developing and using their powers of observation. You can give students freedom in their observation tasks, letting them formulate their own categories and ways of classifying what they see. You can also guide them by telling them to observe specific elements of behaviour. For instance, instruct 
students to use observation to study one or more of the following items:

1. walks

2. arm and hand gestures, facial expressions

3. sitting positions/standing positions

4. breathing movements and sounds

5. space

6. eye contact

7. physical contact

8. people observing their enviromment

\section{Class Discussions and Exercises}

1. Class members report on observations they have made of the culture they are living in. Assign observations in advance, directing students to observe particular people, places, types of interactions, or characteristics.

2. Have learners incorporate actual observations made into fictional character sketch (written, verbal, or performed) of the people involved.

3. Use a picture to stimulate discussion. Find as many visual cues as possible to an interpretation of the characters in the picture. Examine clothing, posture, setting, action, etc.

4. After role playing, scene performances, simulations, and other types of presentations, discuss observations made during the presentations. Have the class apply what they are learning about observation to everyday events. Don't regard the end of a presentation as being the end of the activity.

5. Devote time to each of the five senses (seeing, hearing, smelling, tasting, touching) in isolation. In class, discuss sensations and experiences involving each sense. Also, remind students to try to always incorporate the senses into their movement activities as well as into their discussions.

Therefore, observation prepares students to use their imagination to recognize and appreciate the messages encoded in the vast and complex systems of human behaviour. Language learners can observe in order to discover about the behaviour of a particular individual, or the behaviour of a group of people within a culture, subculture, or situation. They can also observe to broaden their experience and stimulate their imaginations to better understand how humans communicate.

\section{Games, Role-playing, Improvisation, and Simulation}

A variety of techniques can be used to diversify the language learning process: 
Games. Games are frequently used to tighten the group. Through games, the group members become acquainted. The group begins to operate as a unit and its members begin to trust and cooperate. Classmates become teammates, working together to achieve a common goal. Trivia contests, charades, and guessing games are a few games that are ideal for group building.

Role-playing. Role-playing is also a game in the sense that participants play within the confines of previously determined "rules" and scenarios. Two goals of role-playing are to expand the actor's vocabularies of behaviour and to increase their comprehension of a wider range of behaviour in others. Role-playing can be designed to suit a group's language learning needs. The more a person role-plays, the easier it becomes and eventually it can move into improvisation. It is important that the students explore their characters with respect to the incident in a discussion form. This can take place in partners, small groups, or as a class. This adds another dimension to the activity.

Simulation. A simulation is a means of activating the knowledge and language associated with topics the instructor and students are studying. A simulation gives participants the opportunity to practise taking on specific roles and improvising within specific situations. The assumption is that, with practise, the participants will play their roles more effectively when situations involving similar language functions occur in "real life." Simulations are used to train people to communicate and interact in a variety of specific situations. They are effective devices for facilitating communication practise in the language classroom. Language learning takes place in the context of a culture, and "specific" situations. A simulation activity provides a specific situation within which students can practise executing language functions.

\section{Self-esteem}

Self-esteem is on the line in the foreign language classroom much as it is in the emotion-charged atmosphere of a dance rehearsal or performance. Language is a very personal matter - an expression of self. When our ability to express ourselves is reduced, as it is when we use a second language, we risk our psychological well-being every time we try to speak. The language teacher is in a position where he/she can make a difference by helping to preserve one's self-esteem.

Dance gives students a great opportunity for self-expression. At first, students might feel anxious and uncomfortable with activities of selfexpression. In addition, they might find these exercises difficult and requiring a lot of work. Gradually, students become less apprehensive about performance and the activities become easier to deal with. Students start feeling good about themselves and they learn different ways to express 
themselves. It is very important to build this sense of confidence and selfesteem especially for second language learners so that they can learn to feel good about expressing themselves. Second language learners are already at a disadvantage because of the language barrier and there is usually a decrease in confidence and self-esteem. Language teachers can help to build self-esteem for students, and will see that it can alleviate a lot of the pressures that come along with learning a second language. The less anxious individual are, the better they can express themselves which then makes the actual language learning process easier. Thus, dance is an important way to accomplish the goal of establishing and building a good sense of self-confidence and selfesteem for the second language student.

In conclusion, dance provides a number of relationships among various domains of knowledge in terms of second language learning. As demonstrated, the previous techniques mentioned all involve some type of combination of verbal communication along with the movement activities. It is important to practise the speaking component of the language, but it is crucial to incorporate specific tasks to work on the other areas of language which are listening, reading, and writing. These techniques can help everyone become a proficient verbal communicator. Many second language learners rely a great deal on nonverbal actions to communicate ideas. Using various dance techniques to work on the different components of language can help put language learning into more realistic environments. This helps students to relate better to the culture they are living in.

\section{References}

Cook, V. (1996). Second language learning and language teaching. New York, NY: St Martin's Press.

Holden, S. (1981). Drama in language teaching. Harlow, Essex: Longman Group Limited.

Kao, S., \& O'Neill, C. (1998). Words into worlds. Learning a second language through process drama. Stamford, CT: Ablex Publishing Corporation.

Lang, P. (1993). Towards drama as a method in the foreign language classroom. Frankfurt am Main, Germany: Peter Lang.

Miller, J. (1996). The holistic curriculum. Toronto, ON: OISE Press. Smith, S. (1984). The theatre arts and the teaching of second languages. Reading, MT: Addison-Wesley Publishing Company.

Spolsky, B. (1989). Conditions for second language learning. Walton Street, Oxford: Oxford University Press. 